\title{
Pemilihan Parameter Pengecatan Untuk Mendapatkan Ketebalan Lapisan Cat Yang Tepat Untuk Permukaan Tidak Merata
}

\author{
Akhmad Hafizh Ainur Rasyid; Dany Iman Santoso; Firman Yasa Utama \\ Jurusan Teknik Mesin, Fakultas Teknik, UNESA \\ akhmadrasyid@unesa.ac.id \\ danyiman@unesa .ac.id \\ firmanutama@unesa.ac.id
}

\begin{abstract}
Abstrak
Proses pengecatan merupakan proses pelapisan dengan tujuan melindungi dan esetika dari produk yang dilapisi. Agar didapatkan permukaan hasil pengecatan yang bagus diperlukan kondisi permukaan yang bagus pula. Kondisi permukaan yang ada sedikit cacat akan tertutupi bila ketebalan lapisan cat yang menempel pada produk cukup tebal. Ketebalan lapisan cat ditentukan oleh jarak penyemprotan, kecepatan langkah ayun, tekanan spray gun dan tekanan tabung residu. Campuran bahan cat dengan pengencer juga berpengaruh pada ketebalan lapisan namun setiap produsen bahan cat telah memberikan rekomendsi perbandingan campuran yang terbaik. Peneliti menentukan jarak penyemprotan 100;150;200 mm, kecepatan langkah ayun 0,$381 ; 0,448 \mathrm{~m} / \mathrm{s}$, tekanan spray gun 10;12 Psi dan tekanan tabung residu 25;20 Psi. Menggunakan thickness gauge didapatkan ketebalan cat sebesar $0,1 \mathrm{~mm}$ pada jarak penyemprotan $100 \mathrm{~mm}$, kecepatan langkah ayun $0,381 \mathrm{~m} / \mathrm{s}$, tekanan spray gun 12 Psi dan tekanan tabung residu 20 Psi.
\end{abstract}

Kata Kunci: Parameter pengecatan, Ketebalan lapisan.

\begin{abstract}
The painting process is a coating process with the aim of protecting and giving an esthetic of the coated product. In order to get a good painting surface, good surface conditions are needed. The surface conditions that are slightly defective will be covered if the thickness of the paint layer attached to the product is quite thick. The thickness of the paint layer is determined by the spraying distance, swing speed, spray gun pressure and residual tube pressure. The mixture of paints and thinner also has an effect on the thickness of the coating but each manufacturer of paint has provided the best mixed comparison recommendations. Researcher determined spraying distance $100 ; 150 ; 200 \mathrm{~mm}$, swing step speed $0.381 ; 0.448 \mathrm{~m} / \mathrm{s}$, pressure spray gun 10 ; 12 Psi and residual tube pressure 25; 20 Psi. By using a thickness gauge, it is obtained a paint thickness of $0.1 \mathrm{~mm}$ at $100 \mathrm{~mm}$ spraying distance, swing step speed of $0.381 \mathrm{~m} / \mathrm{s}, 12$ Psi spray gun pressure and 20 Psi tube residual pressure.

Keywords: Painting parameters, layer thickness.
\end{abstract}




\section{PENDAHULUAN}

Untuk mendapatkan permukaan hasil pengecatan yang bagus harus diawali dengan persiapan permukaan produk yang baik. Proses pengecatan meliputi beberapa tahapan yaitu persiapan permukaan, aplikasi dempul, pengamplasan, masking, pengoprasian spray gun, pengecatan akhir, membersihkan spray gun, pengkilapan dan pemolesan. Karena bidang pengecatan yang luas atau memiliki bentuk yang tidak merata maka akan sering terjadi sedikit cacat, cacat biasanya baru akan diketahui setelah proses pengecatan akhir sehingga sangat merepotkan pada proses pemolesan. Cacat yang tidak dapat diperbaiki mengharuskan untuk mengulang proses pengecatan sejak awal, karena jika hanya dilakukan penambalan dapat mengurangi estetika.

Proses pengecatan sama halnya dengan proses pelapisan yang mana memiliki ketebalan tertentu. Cacat permukaan biasanya berupa goresan pada proses pengamplasan atau cacat akibat benturan pada saat pengerjaan. Cacat yang sangat sedikit bisa sangat berpengaruh pada hasil akhir pengecatan dan biasanya cacat tersebut diketahui setelah proses pengecatan akhir. Untuk memperbaiki cacat tersebut adalah dengan proses polish namun bila masih nampak cacatnya setelah proses polish maka harus mengulang proses pengecatan dari tahap awal.

Mengulangi proses pengecatan akibat cacat akan sangat menghabiskan waktu dan biaya, karena itu agar cacat dapat diperbaiki pada proses polish maka lapisan yang menempel pada permukaan produk harus cukup tebal. Lapisan cat yang tebal memungkinkan tertutupinya permukaan yang mengalami sedikit cacat.

Berdasarkan permasalah yang ada akan dilakukan penelitian mengenai bagaimana pengaruh jarak penyemprotan, kecepatan langkah ayun, tekanan spray gun dan tekanan tabung residu terhadap ketebalan lapisan cat.

Proses pengecatan yang sering diaplikasikan mempunyai 8 tahapan, yaitu:

Persiapan Permukaan, Merupakan kegiatan untuk mempersiapkan permukaan material yang akan diberi lapisan warna. Persiapan permukaan dapat dilakukan dengan kimiawi, misalnya pengasaman (pickling), membersihkan dengan amplas dan mengkombinasikan dengan semprotan air untuk membasuh semua debu, menghilangkan korosi, dan kotoran dapat larut dalam air.

Aplikasi Dempul, Dempul memiliki 3 jenis

- Polyester putty, umumnya mengandung extender pigment dan dapat membentuk lapisan yang tebal dan mudah mengamplasnya tetapi menghasilkan tekstur kasar.

- Epoxy putty, digunakan untuk memperbaiki resin part tetapi dalam hal kemampuan pengeringan, pembentukan, pengamplasan lebih baik dari polyester

- Lacquer putty, digunakan untuk mengisi goresan, lubang kecil, atau penyok kecil.
Pengamplasan, Pekerjaan mengamplas dapat dimulai setelah pengeringan dempul berakhir, apabila dempul diamplas sebelum dingin, maka kemungkinan akan terjadi pengerutan. Untuk mencegah penggoresan disekitar cat, usahakan pekerjaan pengamplasan hanya dibagian yang ditutup dempul. Jangan mengamplas keseluruhan area sekaligus, tetapi dengan hati-hati sambil memeriksa kerataan permukaan sebelum pengamplasan dilanjutkan

Masking, Prosedur masking dapat diklasifikasikan menurut area lapisan dan tipe dari metode pengecatan yang dijelaskan sebagai berikut:

- Masking untuk aplikasi Surfacer

- Masking untuk Block Repainting

- Masking untuk Shading atau Spot Repainting

- Memilih Border dan metode Masking

Pengoperasian Spraygun, Ada 4 hal penting dalam menggerakkan Spraygun yaitu:

- Jarak Pengecatan

- Sudut Spraygun

- Kecepatan langkah ayun

- Pola tumpang tindihnya atau overlapping

Pengecatan Akhir, Berdasarkan jenis cat, proses pengecatan dapat digolongkan menjadi beberapa macam yaitu Cat Bakar (Heat Polymerization), Cat Two Component (Tipe Urethane), Cat Solvent Evaporation (lacquer)

Membersihkan Spraygun, Proses membersihkan spraygun meliputi dua hal, yaitu bagian luar dan bagian dalam. Pada bagian luar bisa dibersihkan dengan kuas, sedangkan bagian dalam wajib menggunakan thinner dengan udara bertekanan, untuk menjaga semua jalur tetap berfungsi optimal.

Pengkilapan dan Pemolesan, Istilah polishing dalam pengecatan adalah pekerjaan menghaluskan permukaan cat setelah melakukan pengecatan. Hasil dari pengecatan masih banyak terkandung debu dan kemungkinan ketebalan yang tidak rata. Untuk melakukan pemolesan, bisa dilakukan dengan bantuan amplas halus terlebih dahulu (jika permukaan terlalu kasar) atau langsung dengan compound saja (jika permukaan sudah halus). Cara memoles bisa menggunakan tangan manual, atau lebih baik menggunakan alat pemoles yang akan menghasilkan alur yang stabil. Mekanisme Pemolesan yaitu apabila tekstur dari permukaan yang dicat terdapat tonjolan (tekstur kasar-kasar atau bintik yang tampak setelah pengecatan dan pengeringan) pada permukaan yang dicat harus dihilangkan untuk mendapatkan permukaan yang mirip dengan asli cat.

Penggunaan Spray gun Pada Pengecatan

Agar dapat mengecat dengan mantap tanpa menjadi lelah, harus dijaga sikap relaks tanpa memegang bahu, pundak atau lengan yang menahan spray gun. Penggunaan spray gun adalah 
dengan menahan ibu jari, telunjuk dan kelingking, sedangkan trigger ditarik dengan jari tengah dan jari manis.

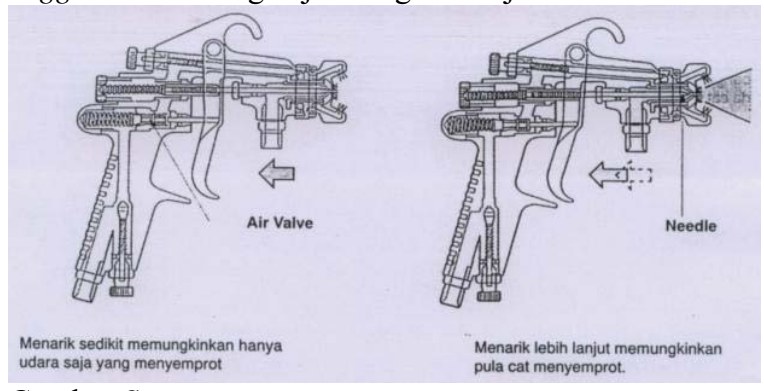

Gambar Spray gun

Ada empat hal penting dalam menggerakkan spray gun, yaitu: (1) jarak spray gun, (2) sudut spray gun, (3) kecepatan langkah ayun, (4) pola tumpang-tindihnya/ over lapping.

- Jarak Pengecatan

Jarak pengecatan atau jarak antara spray gun dan area yang dicat untuk masing-masing cat berbeda, tergantung dari proses dan obyek yang akan dicat. Bila terlalu dekat akan mengakibatkan cat meleleh dan bila terjadi pada cat metalik akan menimbulkan belang-belang yang diakibatkan oleh partikel metalik yang mengumpul. Bila jaraknya terlalu jauh mengakibatkan permukaan menjadi kasar.

Untuk jarak penyemprotan yang tidak teratur akan mengakibatkan hasil pengecatan yang belang-belang dan tidak mengkilap. Jarak spray gun secara umum 15-20 cm, untuk jenis acrylic lacquer : 10-20 cm dan enamel: $15-25$ $\mathrm{cm}$.

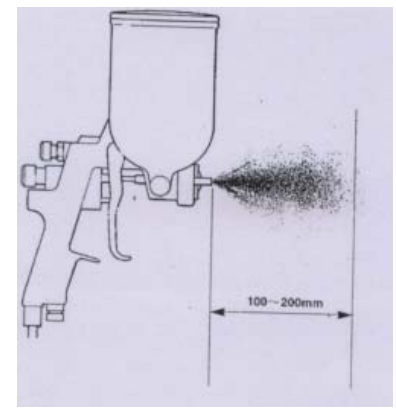

Gambar Jarak Pengecatan

- Sudut Spray gun

Dalam melakukan penyemprotan cat, posisi badan harus diposisikan sejajar dengan benda kerja serta mengikuti dari bentuk benda kerja, mendatar atau melengkung. Arah penyemprotan membentuk sudut $90^{\circ}$ dari bidang kerja. Untuk menghindari kelelahan dalam bekerja, pengecatan dilakukan dari atas ke bawah, bukan dari bawah ke atas.

- Kecepatan Langkah Ayun Pengecatan

Kecepatan gerak alat semprot hendaknya stabil, baik dengan arah horizontal maupun vertikal. Jika terlalu lambat, cat akan meleleh, bila terlalu cepat maka hasil pengecatan kurang rata. Jika kecepatannya kurang stabil maka akan diperoleh hasil pengecatan yang tidak rata dan kurang mengkilap. Kecepatan langkah ayun spray gun harus konstan, yang dianjurkan kira-kira 12 feet/detik.
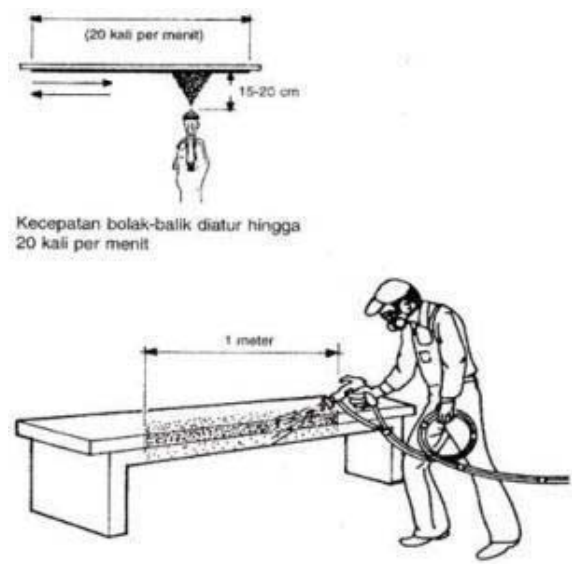

Gambar Kecepatan Pengecatan

- $\quad$ Pola Tumpang Tindih (Over lapping)

Over lapping adalah suatu teknik pengecatan pada permukaan benda kerja, sehingga penyemprotan yang pertama dan berikutnya akan menyambung.

Tujuannya adalah :

- Menghindarkan terjadinya tipis

- Menghindarkan adanya perbedaan warna

- Untuk mendapatkan ketebalan lapisan cat yang merata

- Mencegah tidak adanya cat pada lapisan pertama dan berikutnya

untuk mendapat lapisan merata, maka pola semprotan perlu memiliki ketebalan yang merata pula. Lebar tumang tindih yang pas kira-kira adalah $1 / 2$ sampai $2 / 3$ pola semprotan.

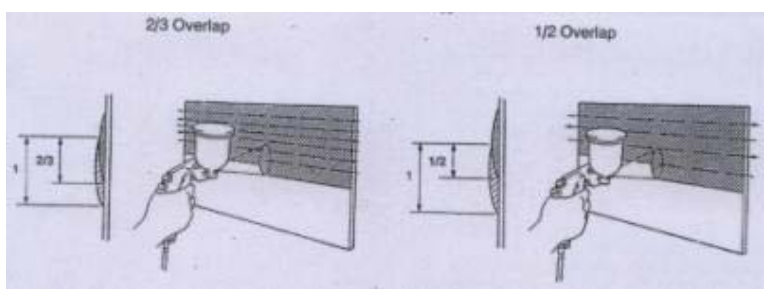

Gambar Proses Over lapping

Over lapping pada bidang vertical, Pada umumnya dilakukan oleh seorang operator secara berkesinambungan. 


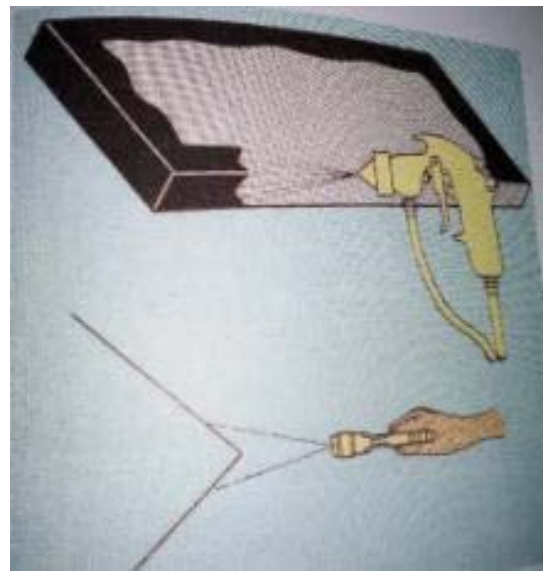

Gambar

Overlapping Bidang Vertikal

Over lapping pada bidang horizontal, Dikerjakan oleh dua orang operator secara berpasangan. Operator A lebih dahulu menyemprot benda kerja, kemudian diikuti oleh operator B

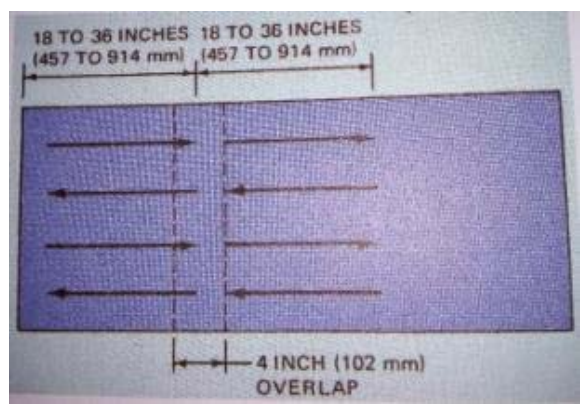

Gambar Over lapping Bidang Horisontal

Over lapping pada bidang permukaan sambungan, Penyemprotan pada bidang perpotongan (misal fender, pintu, $\mathrm{dsb}$ ) perlu diperhatikan pada waktu mulai menyemprot dan berikutnya tidak boleh tepat pada garis perpotongan dan posisi spraygun harus benar-benar tegak lurus. Hal ini dimaksudkan untuk menghindari terjadinya tipis dan meleleh.

Gambar Over lapping Bidang Horizontal

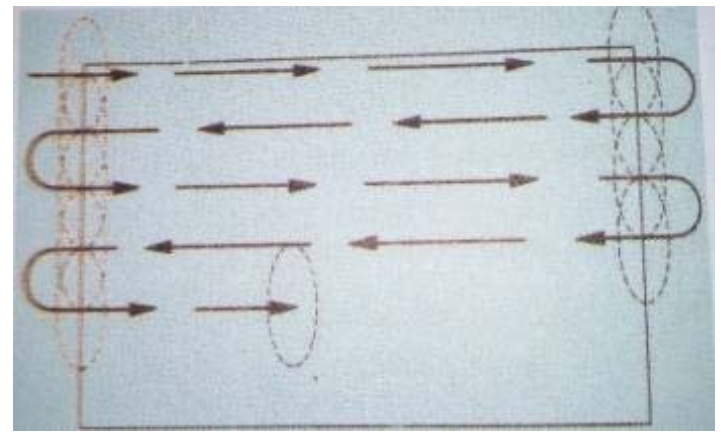

\section{METODE}

Penelitian dimulai dengan mempersiapkan instalasi peralatan yaitu memasangkan selang udara dari kompressor ke spray gun dan menguji fungsinya, melakukan setting jarak penyemprotan tekanan spray gun, tekanan tabung residu dan kecepatan langkah ayun. Instalasi alat ditunjukkan pada gambar berikut:

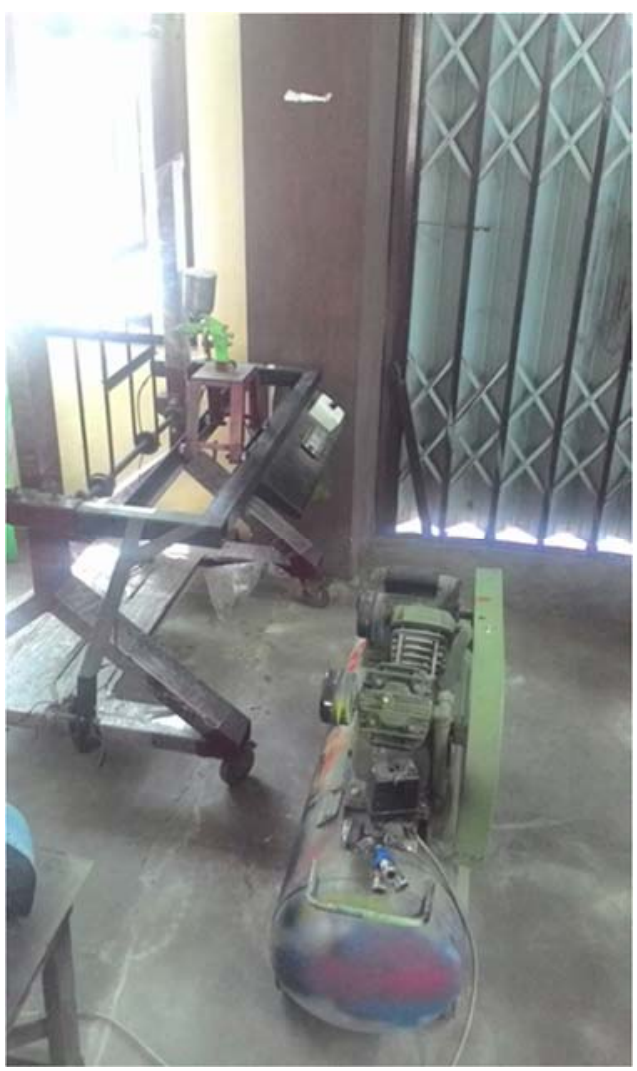

Gambar Instalasi Alat Pengecatan

Instalasi alat diatas dibuat untuk membantu proses penelitian. Pengaturan jarak penyemprotan, kecepatan langkah ayun, tekanan spray gun dan tekanan tabung residu dilakukan pada instalasi tersebut.

Alat ukur diuji coba sebelum dilakukan pengukuran, dalam hal ini adalah thickness gauge. Thickness gauge diuji coba apakah berfungsi atau tidak, berikut gambar uji coba alat:

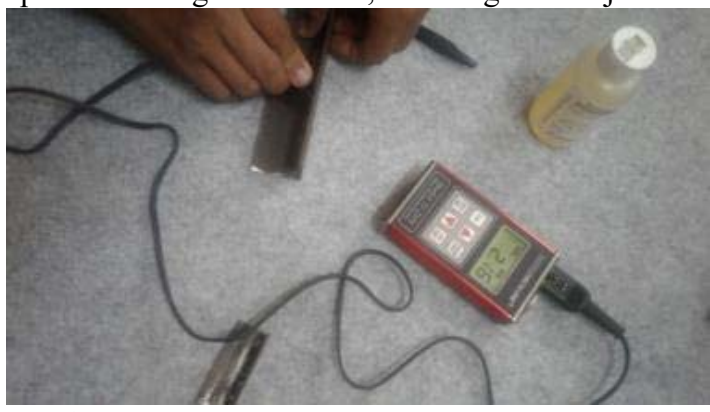

Gambar Uji Thickness Gauge 
Penelitian dilaksanakan melalui beberapa tahap yaitu persiapan benda kerja, persiapan instalasi, pelaksanaan pengecatan dan pengukuran ketebalan lapisan yang kemudian hasilnya dilakukan pembahasan.

\section{HASIL DAN PEMBAHASAN}

Hasil pengambilan data selanjutnya dicatat dan ditabelkan. Data ditunjukkan pada tabel berikut:

Tabel Hasil Penelitian

\begin{tabular}{|c|c|c|c|c|}
\hline $\begin{array}{l}\text { Jarak } \\
\text { Penyem- } \\
\text { protan } \\
(\mathrm{mm})\end{array}$ & $\begin{array}{l}\text { Tekanan } \\
\text { Spray } \\
\text { gun } \\
\text { (Psi) }\end{array}$ & $\begin{array}{l}\text { Tekanan } \\
\text { Tabung } \\
\text { Residu } \\
\text { (Psi) }\end{array}$ & $\begin{array}{l}\text { Kecepatan } \\
\text { Langkah } \\
\text { Ayun } \\
(\mathrm{m} / \mathrm{s})\end{array}$ & $\begin{array}{l}\text { Ketebalan } \\
\text { Cat (mm) }\end{array}$ \\
\hline \multirow[t]{8}{*}{200} & \multirow[t]{4}{*}{10} & \multirow[t]{2}{*}{20} & 0,381 & 0.03 \\
\hline & & & 0,448 & 0.04 \\
\hline & & \multirow[t]{2}{*}{25} & 0,381 & 0.03 \\
\hline & & & 0,448 & \\
\hline & \multirow[t]{4}{*}{12} & \multirow[t]{2}{*}{20} & 0,381 & 0.02 \\
\hline & & & 0,448 & 0.02 \\
\hline & & \multirow[t]{2}{*}{25} & 0,381 & 0.02 \\
\hline & & & 0,448 & 0.02 \\
\hline \multirow[t]{8}{*}{150} & \multirow[t]{4}{*}{10} & \multirow[t]{2}{*}{20} & 0,381 & 0.03 \\
\hline & & & 0,448 & 0.02 \\
\hline & & \multirow[t]{2}{*}{25} & 0,381 & 0.03 \\
\hline & & & 0,448 & 0.03 \\
\hline & \multirow[t]{4}{*}{12} & \multirow[t]{2}{*}{20} & 0,381 & 0.03 \\
\hline & & & 0,448 & 0.04 \\
\hline & & \multirow[t]{2}{*}{25} & 0,381 & 0.04 \\
\hline & & & 0,448 & 0.03 \\
\hline \multirow[t]{6}{*}{100} & \multirow[t]{4}{*}{10} & \multirow[t]{2}{*}{20} & 0,381 & 0.05 \\
\hline & & & 0,448 & 0.05 \\
\hline & & \multirow[t]{2}{*}{25} & 0,381 & 0.05 \\
\hline & & & 0,448 & 0.04 \\
\hline & \multirow[t]{2}{*}{12} & \multirow[t]{2}{*}{20} & 0,381 & 0.1 \\
\hline & & & 0,448 & 0.04 \\
\hline
\end{tabular}

\begin{tabular}{|l|l|l|l|l|}
\hline & \multirow{2}{*}{25} & 0,381 & 0.09 \\
\cline { 3 - 4 } & & & 0,448 & 0.07 \\
\hline
\end{tabular}

Data pada tabel diatas menunjukkan bahwa jarak penyemprotan, tekanan spray gun, tekanan tabung residu, kecepatan langkah ayun berpengaruh terhadap ketebalan cat dan kualitas permukaan. Perubahan paling besar adalah pada jarak penyemprotan $100 \mathrm{~mm}$, tekanan spray gun 12Psi, tekanan tabung residu $20 \mathrm{Psi}$, kecepatan langkah ayun $0,381 \mathrm{~m} / \mathrm{s}$ dengan perubahan ketebalan cat $0,1 \mathrm{~mm}$.

Jarak penyemprotan merupakan parameter yang paling berpengaruh. Tekanan pada tabung residu yang tinggi menyebabkan campuran miskin antara bahan cat dengan udara, sehingga lapisan yang mengenai permukaan benda menjadi tipis, berbeda dengan tekanan spray gun yang berpengaruh pada kecepatan pengiriman campuran cat dari sprau gun ke permukaan benda kerja, semakin tinggi tekanan semakin cepat pengiriman, semakin rendah semakin lambat sehingga sebagian partikel cat tidak terkirim tetapi tertahan diudara atau jatuh. Bila partikel cat tidak terkirim dengan sempurna maka lapisan cat yang menempel menjadi tipis. Hasil ini sesuai dengan rekomendasi yang terdapat pada teori yaitu 100-200 mm untuk jenis acrylic lacquer.

\section{SIMPULAN}

Simpulan yang dapat diambil dari kegiatan penelitian yang sudah dilakukan adalah:

- Jarak penyemprotan berpengaruh terhadap kualitas permukaan dan ketebalan cat dimana parameter optimum pada jarak penyemprotan $100 \mathrm{~mm}$, tekanan spray gun $12 \mathrm{Psi}$, tekanan tabung residu 20Psi.

- Kecepatan langkah ayun pengecatan berpengaruh terhadap kualitas permukaan dan ketebalan cat dimana parameter optimum pada kecepatan langkah ayun $0,381 \mathrm{~m} / \mathrm{s}$, tekanan spray gun 12 Psi, tekanan tabung residu 20Psi.

\section{Saran}

Proses pengecatan merupakan proses yang sederhana namun memiliki banyak faktor penunjang agar dapat diselesaikan dengan baik, karena itu beberapa saran yang mungkin kami berikan adalah:

- Dilakukan penelitian lebih lanjut mengenai pengaruh tekanan spry gun pada proses pengecatan.

- Dilakukan penelitian lebih lanjut mengenai pengaruh tekanan tabung residu pada proses pengecatan.

- Dilakukan optimalisasi dari berbagai parameter pengecatan sehingga didapatkan tabel standar parameter pengecatan yang nantinya dapat digunakan sebagai acuan. 


\section{REFERENCE}

Temukan Pengertian. (2016, Januari). Pengertian proses produksi. Diperoleh 6 April 2017, dari http:// www.temukanpengertian.com/2016/01/pengertian-prosesproduksi/

Ep, Bayu., 2016, Metode Pengukuran Kualitas Cat, [online], (http://uji.co.id/metode-pengukuran-kualitas-cat/. Htm, diakses tanggal 6 april 2017)

Santosa, Bambang dan Martijanti Syamsa., 2007, Pengaruh Parameter Proses Pelapisan Nikel terhadap Ketebalan Lapisan. Diperoleh 6 april 2017, dari (http://jurnalmesin.petra.ac.id/index.php/mes/article/download/1 6642/16634/. Pdf, diakses tanggal 6 april 2017)

Dg Paniki. (2012, Maret). Pengantar Teknik Optimasi. Diperoleh 6 april 2017, dari http://dgpaniki.blogspot.co.id/2012/03/pengantar-optimasibab1-pendahuluan-1.html/

Sunadi. 2011. Pengecatan Ulang Bodi Kendaraan. Yogyakarta: PT Citra Aji Parama 